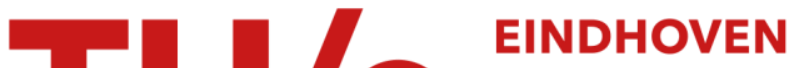 UNIVERSITY OF TECHNOLOGY
}

\section{Experimental investigation of the thermal interactions of nucleation sites in flow boiling}

\section{Citation for published version (APA):}

Baltis, C. H. M., \& Geld, van der, C. W. M. (2014). Experimental investigation of the thermal interactions of nucleation sites in flow boiling. International Journal of Heat and Mass Transfer, 78, 2008-2018. https://doi.org/10.1016/j.ijheatmasstransfer.2014.07.076

DOI:

10.1016/j.ijheatmasstransfer.2014.07.076

Document status and date:

Published: 01/01/2014

\section{Document Version:}

Publisher's PDF, also known as Version of Record (includes final page, issue and volume numbers)

\section{Please check the document version of this publication:}

- A submitted manuscript is the version of the article upon submission and before peer-review. There can be important differences between the submitted version and the official published version of record. People interested in the research are advised to contact the author for the final version of the publication, or visit the $\mathrm{DOI}$ to the publisher's website.

- The final author version and the galley proof are versions of the publication after peer review.

- The final published version features the final layout of the paper including the volume, issue and page numbers.

Link to publication

\section{General rights}

Copyright and moral rights for the publications made accessible in the public portal are retained by the authors and/or other copyright owners and it is a condition of accessing publications that users recognise and abide by the legal requirements associated with these rights.

- Users may download and print one copy of any publication from the public portal for the purpose of private study or research.

- You may not further distribute the material or use it for any profit-making activity or commercial gain

- You may freely distribute the URL identifying the publication in the public portal.

If the publication is distributed under the terms of Article 25fa of the Dutch Copyright Act, indicated by the "Taverne" license above, please follow below link for the End User Agreement:

www.tue.nl/taverne

Take down policy

If you believe that this document breaches copyright please contact us at:

openaccess@tue.nl

providing details and we will investigate your claim. 


\title{
Experimental investigation of the thermal interactions of nucleation sites in flow boiling
}

\author{
Coen Baltis, Cees van der Geld* \\ Eindhoven University of Technology, Department of Mechanical Engineering, P.O. Box 513, 5600 MB Eindhoven, The Netherlands
}

\section{A R T I C L E I N F O}

\section{Article history:}

Received 19 May 2014

Received in revised form 24 July 2014

Accepted 24 July 2014

Available online 15 August 2014

\section{Keywords:}

Boiling

Bubbles

Heat transfer

Forced convection

Nucleation site interaction

\begin{abstract}
A B S T R A C T
An experimental setup was designed to perform nucleate boiling experiments in upward saturated flow conditions, in order to investigate the influence of vertically aligned vapor bubble nucleation sites on one another. Experiments were performed by activating two bubble generators, of which the inter-site distance can be varied by steps of $2 \mathrm{~mm}$. Depending on mass flow rate, flow direction and heat fluxes to both bubble generators, nucleation sites have been shown to interact at any nucleation site distance. The results have shown two major trends. The first trend is caused by additional convection (not by bubbles) from the upstream bubble generator, BG2, to the downstream bubble generator, BG1, increasing its nucleation frequency and bubble detachment diameter. The influence of additional convection on bubble frequency and diameter diminishes with increasing inter-site distance, $S$, and initial bubble nucleation frequency at BG1. The influence of added convective heat is enhanced by increasing the liquid bulk flow rate. The second trend is seen when BG2 initiates its own bubble nucleation. Vapor bubbles that nucleate at BG2 and pass by BG1 in close proximity have an inhibitive effect on bubble nucleation at BG1. The effect of this inhibitive trend diminishes with increasing nucleation frequency at BG1. Because of the significance of the effect of hydrodynamic interaction on the number of active nucleation sites and bubble size at detachment, mechanistic modeling of nucleate flow boiling is expected to benefit from the quantifications presented in this study.
\end{abstract}

(c) 2014 Elsevier Ltd. All rights reserved.

\section{Introduction}

Nucleate boiling is a very efficient mode of heat transfer, yet many aspects of nucleate boiling are not well understood even today. Understanding of basic physical phenomena involved in nucleate boiling is essential to come to mechanistic models of nucleate boiling which yield realistic predictions. Note that even though such models were actively pursued $[1,2,3,4]$ the predictive capacity is still poor, as shown by Kroes et al. [5] and Moghaddam \& Kiger [6]. Interactions between vapor bubble nucleation sites form an important part of nucleate boiling heat transfer. In the past, many researchers studied nucleation site interactions in pool boiling, which provided better insight in the phenomenon. Unfortunately, nucleation site interactions in forced convection, which is the main topic of this study, have never been studied before.

One of the earliest researches to nucleation site interactions in pool boiling was reported by Zuber [7]. He described interactions

\footnotetext{
* Corresponding author.

E-mail addresses: c.h.m.baltis@tue.nl (C. Baltis), c.w.m.v.d.geld@tue.nl (C. van der Geld).
}

in boiling from a flat plate with natural nucleation sites. He concluded that, with relatively low to moderate nucleation site density, the mean bubble departure size is more or less constant at all sites. He defined this as the isolated bubble region. With increasing nucleation site density, the bubble departure size starts decreasing after reaching a certain limit value in active nucleation sites per square meter; this region he named the interference region. Nucleation site interactions were thought to be the cause of this decrease in bubble size.

Zuber studied boiling on a flat plate with many natural nucleation sites. However, Chekanov [8] was one of the first to report a study of interactions between individual nucleation sites in pool boiling. Using a thin metal foil and two pointed heaters, he was able to vary the distance between active nucleation sites in water. He did not visualize individual bubbles by camera but used sound recordings to register bubble nucleation events. His results appear to disagree with later findings by others, as discussed below. The heat flux in Chekanov's went as high as the critical heat flux.

Calka and Judd [9] reproduced the experiment of Chekanov in dichloromethane. The ratio between inter-site distance, $S$, and mean bubble diameter, $\bar{D}_{b}$, was used as the main parameter to 
define regions of influence. Surprisingly, their conclusions did not agree with the conclusions of Chekanov. Calka and Judd found that for $S / \bar{D}_{b}>3$ no interactions occurred, for $1<S / \bar{D}_{b}<3$ bubble nucleation is inhibited and for $S / \bar{D}_{b}<1$ there is promotion. Calka and Judd claimed that nucleation sites promote each other by a seeding mechanism, only occurring when $S / \bar{D}_{b}<1$; when a vapor bubble grows over an inactive nucleation site, this site can be activated by leaving behind vapor and, thereby, initiating nucleation. Curiously enough, no explanation was given for the hypothesis that the region where $1<S / \bar{D}_{b}<3$ is of an inhibiting nature.

Kenning and Del Valle [10] hypothesized on areas of influence for nucleation sites as well. In their surface quenching model they estimated the degree of overlap defined by three parameters and incorporated short range nucleation site interactions. Their experimental data seemed to indicate inhibition of bubble nucleation on neighboring sites within the $S / \bar{D}_{b}<1$ range, a conclusion agreeing with Chekanov.

Bonjour et al. [11] more specifically studied the phenomenon of coalescence of two vapor bubbles growing on two neighboring artificial sites in pool boiling. At low heat fluxes, nucleation sites would not generate bubbles simultaneously but alternately, likely caused by heat conduction in the substrate. At higher heat fluxes, bubbles would grow independently and often coalesce. By varying the heat flux and inter-site distance, the remarkable conclusion was drawn that the highest heat transfer rate was observed when the inter-site distance was sufficiently large to avoid coalescence. An ideal site spacing of roughly $0.5<S / \bar{D}_{b}<1.5$ was found, but Bonjour suggested that the ideal spacing should also be dependent on the Jakob number, Ja, which is expectable because bubbles are known to increase in size with increasing Jakob number. This conclusion would indicate that heat transfer is decreased by bubble coalescence.

Zhang \& Shoji [12] analyzed the interaction of nucleation sites in pool boiling and described three main factors of influence: (1) Hydrodynamic interactions between vapor and liquid, (2) bubble coalescence and (3) thermal conduction in the surface material. The main conclusions from their analysis are that thermal interactions inhibit bubble nucleation and both hydrodynamic interaction and coalescence are promotive. Furthermore, it was concluded that coalescence was only observed when $S / \bar{D}_{b}<1.5$ and thermal interactions via the wall occurred for $S / \bar{D}_{b}<2$. When $S / \bar{D}_{b}>3$ there were no nucleation site interactions. These results roughly agreed to Calka and Judd [9], described above.

Many more studies followed in recent years. Bubble coalescence was studied by Mukherjee and Dhir [13], Siedel et al. [14] and Golobič et al. [15]. Luke [16] researched the influence of surface roughness of steel and copper tubes on the number of active nucleation sites. Lastly, Nimkar et al. [17] performed tests on grids of artificial cavities with varying spacing. He came to an optimal nucleation site spacing of $1.5<S / \bar{D}_{b}<2$. This range is higher than Bonjour [11] concluded, but that research was performed on a vertical surface and limited to only 2 or 3 neighboring nucleation sites.

Obviously, over the past 60 years much research has been done to nucleation site interactions. It has proven to be quite a challenge to provide reliable data with an accurate quantitative analysis. Even defining factors of influence and their importance are still up for debate. What stands out, is that all research on this subject has been performed in pool boiling. However, most cooling applications rely on forced convective heat transfer. To increase knowledge and insight in the phenomena involved in nucleation site interactions, it is therefore important to extend research to forced convective boiling. Hopefully, this will also provide a better understanding of the hydrodynamic interactions involved in pool boiling.

The experiments reported in this work were designed to assess the interactions between individual nucleation sites in upward saturated flow conditions. First, an overview of the experimental equipment and methods is given. Next, the main results of the experiments are described. Last, the results are analyzed and discussed, followed by the main conclusions.

\section{Experimental methods and procedures}

\subsection{Test setup}

In order to perform measurements in saturated flow conditions, a closed-loop experimental setup was designed. The setup allows for accurate control of flow, temperature and pressure of the bulk fluid, which is demineralized water. Furthermore, the setup is constructed in a way that allows for optimal deaeration of the liquid, prior to initiation of experiments. Because the working fluid is demineralized water, the setup has been constructed using stainless steel 316L to avoid corrosion. Flexible connections between up- and downflow channels and the pump have been applied to avoid stresses in the main flow channel caused by thermal expansion.

A schematic of the test setup and its components can be seen in Fig. 1. During the description of the test setup below, references to the components in the schematic will be given by use of "(\#)".

\subsubsection{Flow}

The pump (2) is a frequency controlled Grundfos CRNE 5-2 vertical centrifugal pump and is capable of delivering a maximum flow rate $\left(Q_{\max }\right)$ of $3.24 \mathrm{~m}^{3} / \mathrm{hr}$, which corresponds to a mean bulk velocity $\left(v_{\text {bulk }}\right)$ in the test section (4) of $1 \mathrm{~m} / \mathrm{s}$. The pump is positioned 4 meter below the test section, which increases the local pressure by 0.4 bar and prevents the pump from cavitating. The flow meter (3) is positioned upstream of the test section and measures the flow using ultrasonic waves (Krohne UFM 3030). This type of measurement does not disturb the flow and causes an insignificant pressure drop, both of which are important advantages. The flow meter has an expected measurement error of $0.5 \%$ of the measured value.

The upflow channel and test section have a cross section of $30 \times 30 \mathrm{~mm}^{2}$. To ensure fully developed flow conditions in the test section, the free flow length in front of the test section is 40 hydraulic diameters long and preceded by a tube bundle flow straightener. Furthermore, the flow meter, which is positioned before the flow straightener, has a contraction which is also known to be advantageous for flow development.

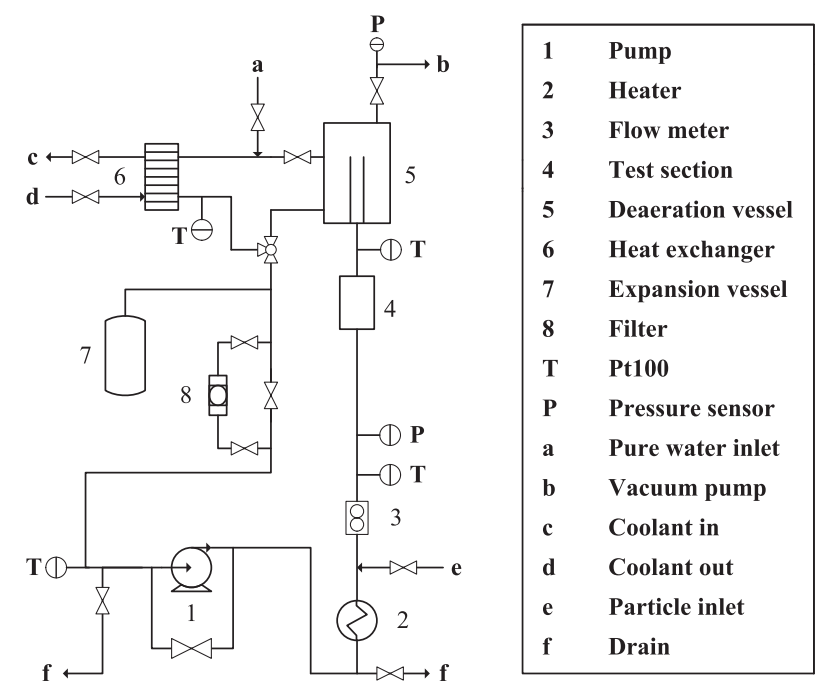

Fig. 1. Schematic of the test setup. 


\subsubsection{Temperature}

Accurate temperature control is vital for boiling experiments. In order to minimize heat losses, the complete setup has been insulated using $6 \mathrm{~mm}$ thick Armaflex ${ }^{\circledR}$. During the main experiments, this insulation was found to be sufficient since the difference in temperature between heater and test section (4 meters in length) was $0.2 \mathrm{~K}$ at maximum. The fluid is heated up by an immersion heater (2) of $17 \mathrm{~kW}$. In order to maintain a steady fluid temperature with $0.1 \mathrm{~K}$ accuracy, a Pt100 is positioned right above the test section and connected to a Eurotherm $^{\circledR} 2408$ PID controller which regulates the heater. The temperature measurement has been calibrated in a controlled environment to the value of a certified Pt100, yielding an accuracy of $\sim 0.1 \mathrm{~K}$. A plate heat exchanger (6) with a maximum capacity of $30 \mathrm{~kW}$ can be utilized to cool down the liquid when desired.

The orientation and placement of the heater are chosen such that any hot liquid and bubbles, as a result of degassing, will rise straight up past the test section and into the deaeration vessel (5), which separates air bubbles from water by buoyancy. Any remaining microbubbles are captured by a Spirovent ${ }^{\circledR}$ deaerator. The setup is deaerated by circulating the water at a temperature of $101{ }^{\circ} \mathrm{C}$ at ambient pressure for several hours.

\subsubsection{Pressure}

The system pressure is monitored by a pressure transducer $(\mathrm{P})$ which has an accuracy of 0.01 bar. To stabilize the pressure, an expansion vessel (7) with pressure control on the air-side of the vessel is employed.

\subsection{Test section}

The test section used during the experiments has been custom made to meet all requirements. First and foremost, the test section has to contain nucleation sites for vapor bubbles to grow at specific spots onto which cameras can be directed. Special requirement of these nucleation sites is that the temperature of the wall can be measured. Second, clear undistorted views of the vapor bubbles and flow are of great importance to the accuracy of measurements. Third, any materials used in this design have to be able to withstand the system temperature range and chemically resist the working fluid. These requirements led to the design presented below.

\subsubsection{Vapor bubble generation}

Due to the requirement of temperature measurement or temperature control of the bubble nucleation area, choice was made for $1 \times 1 \mathrm{~mm}^{2}$ titanium thin film resistors with a thickness of $200 \mathrm{~nm}$ as bubble nucleation sites, with a typical resistance of $10 \Omega$. The resistance of these thin films is sensitive for temperature fluctuations, with an average positive temperature coefficient of resistance (TCR) of $0.001 \mathrm{~K}^{-1}$. This TCR value is lower than the bulk TCR known from literature $\left(0.0038 \mathrm{~K}^{-1}[18]\right)$. The reason for the lower TCR is its dependence on film thickness, see for example Belser \& Hicklin [19], who reported a decrease in temperature coefficient for various thin metal films of similar thicknesses by up to 0.02 times the bulk TCR.

When the resistance changes, any current and voltage flowing through the resistor will also change. By keeping the current through this resistor constant and measuring the voltage drop, its resistance and, therefore, temperature can be determined.

The thermal response time of the titanium layer and the glass substrate underneath follows from the analytical solution of the heat equation for a semi-infinite solid with a boundary condition of the third kind, given by Luikov [20, Chap. 6, pp. 201-208] as

$$
\begin{aligned}
\theta(x, t)= & \operatorname{erfc}\left(\frac{x}{2 \sqrt{\alpha_{s} t}}\right)-\exp \left[\frac{\overline{h_{c}} x}{k_{s}}+\frac{\bar{h}_{c}^{2} \alpha_{s} t}{k_{s}^{2}}\right] \\
& \cdot \operatorname{erfc}\left\{\frac{x}{2 \sqrt{\alpha_{s} t}}+\frac{\overline{h_{c}} \sqrt{\alpha_{s} t}}{k_{s}}\right\}
\end{aligned}
$$

in which $\alpha_{s}$ is the thermal diffusivity of the wall material, $k_{s}$ the thermal conductivity of the wall material, $\bar{h}_{c}$ is the average heat transfer coefficient over the length of the thin film resistor, and $\theta(x, t)$ is defined as $\left(T(x, t)-T_{0}\right) /\left(T_{\text {bulk }}-T_{0}\right)$, with $T_{0}$ the initial wall temperature and $T_{b u l k}$ the bulk liquid temperature. Length $x$ is the depth into the wall material, with $x=0$ defined as the liquid-solid interface. In the following simplifying estimation of the thermal response time of the titanium layer, $\tau_{T F}$, the wall material is assumed to be all glass. This will yield an overestimation of $\tau_{\text {TF }}$.

The only unknown in Eq. (1) is the average convective heat transfer coefficient, $\bar{h}_{c}$, over the length of the thin film resistor, given by

$\bar{h}_{c}=q^{\prime \prime} /\left(T_{T F}-T_{b u l k}\right)$,

in which $q^{\prime \prime}$ is the heat given to the liquid flow past the thin film resistor per square meter, $T_{T F}$ is the mean temperature of the thin film resistor. Typical values as seen during experiments are $q^{\prime \prime}=0.5 \mathrm{MW} / \mathrm{m}^{2}$ and $T_{T F}-T_{\text {bulk }}=15 \mathrm{~K}$. This results in $\overline{h_{c}}=33 \times$ $10^{3} \mathrm{~W} /\left(\mathrm{m}^{2} \mathrm{~K}\right)$.

The thermal response time is defined as the time at which the wall temperature at a depth of $200 \mathrm{~nm}$ (i.e. the thickness of the titanium layer) is at $95 \%$ of the wall temperature at $x=0$. Solving Eq. (1) for $\theta(x=0, t)$ and $\theta\left(x=2 \times 10^{-7}, t\right)$ and setting the ratio of these two values to $95 \%$, a thermal response time $\tau_{T F}=23 \mu \mathrm{s}$ is obtained. If anything, this value is an overestimation since it was calculated using the thermal properties of the glass substrate, while the material of the thin film resistor is titanium, which has a much higher thermal diffusivity. The above overestimation outweighs any uncertainty in the material properties, which have therefore not been accounted for

Owing to the small thermal response time, the instantaneous mean thin film temperature, $T_{T F}$ can be accurately determined by measuring its resistance.

\subsubsection{Bubble generator test section}

The test section consists of a glass channel with a square cross section of $30 \times 30 \mathrm{~mm}^{2}$. On one wall of the channel, a grid of thin film resistors has been placed by chemical vapor deposition. By the same process, golden leads with a thickness of $500 \mathrm{~nm}$ have been deposited, which act as electric conductors. It should be noted here that the temperature dependence of the golden leads has been measured independently, in another setup, and was found to be negligible. The low resistance of the golden leads as compared to

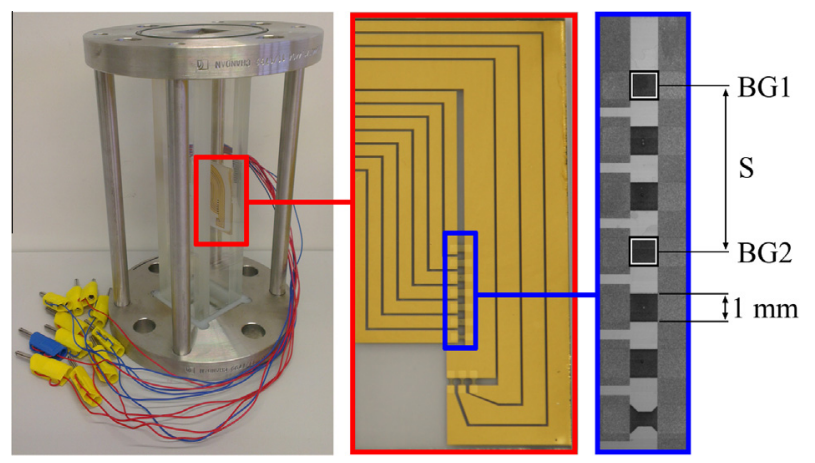

Fig. 2. (Left) Glass test section, (Middle) Bubble generator grid, (Right) Close-up view of the grid. 
that of the titanium resistors explains this finding. A picture of the test section can be seen in Fig. 2, along with the main bubble generator grid and a close-up view of this grid.

The vertical spacing between each of the top seven bubble generators is $1 \mathrm{~mm}$. They are positioned in the horizontal center of the wall. The bottom three generators are placed horizontally, also with a spacing of $1 \mathrm{~mm}$. Measurements have shown that these bottom three bubble generators have no influence on each other in terms of bubble nucleation frequency or bubble detachment diameter. The only conclusion that can be drawn with respect to the horizontal influence of nucleation sites in upward flow boiling is that there are no nucleation site interactions when the $S / D_{b}$ ratio is 1.33 or larger. Therefore, the remainder of this study will be about the top seven (vertically aligned) bubble generators.

An important note to make here, is that all bubble generators are connected to a common exit lead. In the next section, this exit lead will be shown to play a significant role in the determination of the bubble generator resistances.

\subsection{Data acquisition and control system}

Power is fed to the bubble generators by constant current (CC) power sources. The voltage drop over the bubble generators is measured at a sampling frequency of $10 \mathrm{kHz}$. Application of Ohm's law $(V=I R)$ then yields the resistance of the bubble generator. The complete electric scheme can be seen in Fig. 3. The voltages, $V$, in this scheme are measured with respect to a common ground. Resistances $R_{S 1}$ and $R_{S 2}$ are shunt resistances with a known value, used to determine the current, $I$, through the bubble generators $R_{B G 1}$ and $R_{B G 2}$.

The common exit resistance, $R_{\text {exit }}$, has a significant influence on the results. Only when this resistance of the exit lead is known exactly, there is no influence of this resistance on the calculation of $R_{B G 1}$ and $R_{B G 2}$. Calculation of the resistances on BG1 and BG2 is done by

$R_{B G 1}=\left(V_{1}-V_{e x i t}\right) / I_{1}$, where

$V_{\text {exit }}=\left(I_{1}+I_{2}\right) R_{\text {exit }}=\left(V_{S 1} / R_{S 1}+V_{S 2} / R_{S 2}\right) R_{\text {exit }}$,

in which $V_{1}, V_{S 1}$ and $V_{S 2}$ are measured, and $R_{S 1}$ and $R_{S 2}$ are known. Both bubble generator resistances can be determined by varying $I_{2}$ and keeping $I_{1}$ constant.

The accuracy of the determination of the resistances $R_{\text {exit }}, R_{B G 1}$ and $R_{B G 2}$ was assessed by replacing these resistances by known resistances with similar values. For the case of a single active bubble generator, where $I_{1}$ was varied and $I_{2}=0$, it was found that the error in $R_{B G 1}+R_{\text {exit }}$ is a function of $I_{1}$ and is around $0.01 \Omega$ for $I_{1} \geqslant 0.1 \mathrm{~A}$. In the experiments presented in this paper, the current through BG1 was at least $0.2 \mathrm{~A}$. For this reason, the expected error in its resistance is a maximum of $0.01 \Omega$. When both current sources are active, the accuracy of the value of $R_{\text {exit }}$ plays a significant role in the determination of $R_{B G 1}$ and $R_{B G 2}$, as can be deducted

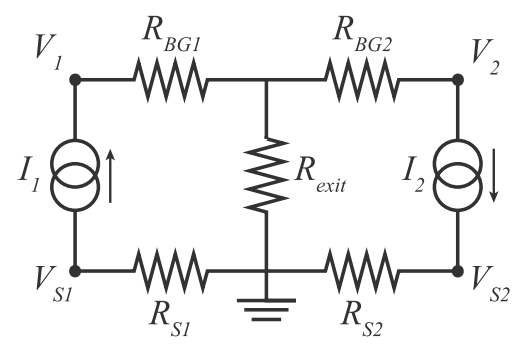

Fig. 3. Electrical scheme as applied during the experiments, allowing determination of the instantaneous resistances and powers when operating two bubble generators simultaneously. from Eqs. (3) and (4). By varying $I_{2}$ at a constant current $I_{1}=0.1 \mathrm{~A}$, it was found that $R_{\text {exit }}$ can also be determined up to $0.01 \Omega$ accuracy. However, the sign of the error is important. An over- or underestimation of $R_{\text {exit }}$ by $0.01 \Omega$ will result in either a linearly increasing or decreasing error in the bubble generator resistances as function of current $I_{2}$. This error has a maximum of $0.02 \Omega$ at $I_{2}=0.25 \mathrm{~A}$, which is the maximum current used during the experiments. The conclusion of this error analysis, is that the resistance of a single active bubble generator can be determined with a precision of $0.01 \Omega$. When two bubble generators are active, there is an additional error which can cause an increasing or decreasing linear trend in the resulting resistance of both bubble generators, with a maximum of $0.02 \Omega$. The implications for temperature determination of the bubble generators are obvious. A precision of $0.01 \Omega$ corresponds roughly to a precision of $1 \mathrm{~K}$, which is also the precision of a single active bubble generator. When two bubble generators are active, the upward or downward trend corresponds to a maximum precision of $\pm 2 \mathrm{~K}$. In the reported experiments below (Section 3), the variation in resistance of BG1 was within $0.02 \Omega$. Owing to the above analysis, the only conclusion that may be drawn from the electric measurements of the wall temperature, $T_{\text {wall }}$, when two bubble generators are heated is that temporal variations in temperature of BG1 are within $\pm 2 \mathrm{~K}$ during all experiments.

The acquisition of the electrical data is synchronized with an optical acquisition system consisting of a camera and two light sources, as shown in Fig. 4. The camera (Photron SA3, 5000 FPS) records the nucleating bubbles from the top. A $50 \mathrm{~W}$ LED (Bridgelux $^{\circledR}$ ) is placed directly opposite to the camera but direct shadowgraphy is impossible due to the titanium and golden layers blocking the light from the back. Therefore, a Dedocool, placed above the camera, is used for extra lighting from the top.

The geometrical calibration of the top view camera images is done with the observed grid of bubble generators (see Fig. 2), which allows for an accurate pixel to millimeter conversion. From this calibration, a pixel to millimeter conversion is typically found to be $22 \pm 0.05 \mu \mathrm{m} / \mathrm{px}$. This calibration is performed before each measurement.

\subsubsection{Bubble frequency}

The bubble frequency is one of the main parameters reported in the results section. The frequency is determined by analysis of the voltage drop across the bubble generator. When a bubble nucleates on a bubble generator, it draws heat from the titanium thin film and the glass underneath. This cools down the resistor and, as described in Section 2.2, lowers its resistance. Since the current

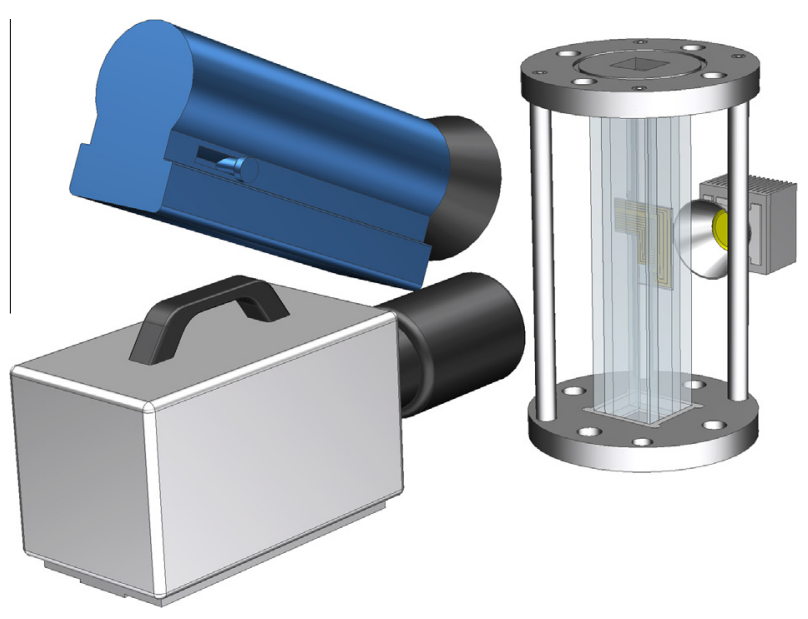

Fig. 4. Main optical configuration used during the experiments. 
is kept constant and the resistance decreases, the voltage must also decrease as prescribed by Ohm's law $(V=I R)$. An example measurement is presented in Fig. 5. The data, in gray, is smoothed using a 100-point moving average, resulting in the black line.

In Fig. 5, a total of 15 bubbles nucleated in $1 \mathrm{~s}$, each of which caused a voltage drop of around $4-5 \mathrm{mV}$. In the analysis, the derivative of the signal is taken and, in combination with a suitable threshold value, the bubble frequency is extracted from these data. In the experiments reported below, the bubble frequency was determined over a time span of $30 \mathrm{~s}$ per measurement point. In the results section, the accuracy in the frequency is given by the standard error of the mean. The frequency is the reciprocal of the average waiting time, $\overline{\tau_{w}}$, for which the standard error of the mean for a finite set of $N$ samples is given by

$s_{\bar{x}}=\sqrt{\frac{1}{N(N-1)} \sum_{i=1}^{N}\left(\tau_{i}-\overline{\tau_{w}}\right)^{2}}$.

It was found that the actually activated natural nucleation site on BG1 varied between experiments. The above analysis of bubble frequency was applied to the experiments reported for the lowest flow velocity, $v_{\text {bulk }}=0.45 \mathrm{~m} / \mathrm{s}$, in which BG1 produced relatively large $(\sim 2 \mathrm{~mm})$ bubbles causing a significant voltage drop. However, a different nucleation site was active on BG1 in the measurements at the higher flow velocity $0.85 \mathrm{~m} / \mathrm{s}$, as described in more detail in the results Section 3. This nucleation site produced smaller bubbles and, therefore, caused less significant voltage drops, making accurate nucleation frequency determination difficult. Therefore, the nucleation frequencies for these measurements have been determined from $10 \mathrm{~s}$ camera recordings.

\subsubsection{Bubble detachment diameter}

The second parameter reported in the results section is the bubble detachment diameter, $D_{b}$. This diameter is determined at detachment by taking the average of two lengths in camera images, shown in Fig. 6.

The accuracy of lengths $a$ and $b$ is 1 pixel, which corresponds to $0.022 \mathrm{~mm}$, or ca. $1-2 \%$ of length a or b. The diameter determined from $a$ and $b$ is different from a volume equivalent diameter since the bubble height normal to the wall is not taken into account. The sole purpose of the diameter chosen is to have a length scale with which to discriminate between bubbles generated under various conditions.

\subsection{Measurement strategy}

During all experiments, the bulk liquid temperature, $T_{b u l k}$, was around $101.0 \pm 0.1{ }^{\circ} \mathrm{C}$ and the local bulk pressure, $p_{b u l k}$, at the

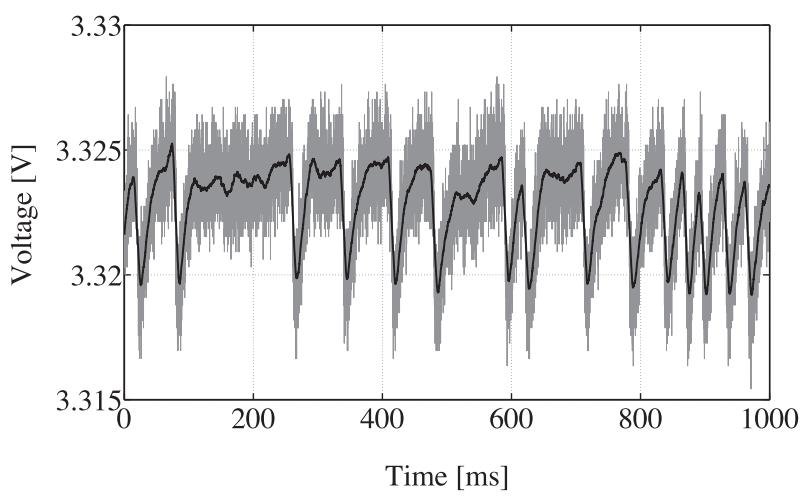

Fig. 5. Typical voltage measurement across a bubble generator, the sharp voltage drops are caused by bubble nucleation.

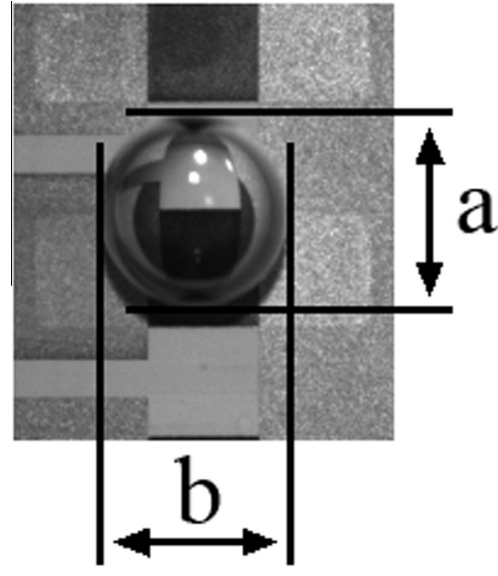

Fig. 6. Bubble detachment diameter determination.

height of bubble generator grid was 1.05 bar. These values meet near saturation conditions. The main objective of the experiments is to study the influence of one bubble generator on another one. Therefore, two bubble generators are heated at the same time. As mentioned in Section 2.2, only the top seven bubble generators (see Fig. 2) are discussed in the results section. For all experiments presented in the results section, the power to the top bubble generator (i.e. the generator positioned highest, from here on referred to as "BG1") is kept constant. The second bubble generator, positioned upstream from BG1, is labeled "BG2". The power fed to BG2 is varied during the experiments, and is incrementally increased from $0 \mathrm{~W}$ to the point where the bubble frequency at this bubble generator is roughly $100 \mathrm{~Hz}$. This limit was chosen because of the fragile nature of the thin films; when the layer does not get sufficient cooling, it can locally overheat and break. The second variable in the experiments is the inter-site distance, $S$, which is defined as the distance between the centers of the bubble generators. It should be stressed that bubbles do not necessarily nucleate from the exact center of the bubble generator. The value of the inter-site distance is varied from 2 to $10 \mathrm{~mm}$. Lastly, the bulk flow velocity, $v_{\text {bulk }}$, is varied in order to study the influence of this parameter on inter-site heat transport. The investigated flow velocities are 0.45 and $0.85 \mathrm{~m} / \mathrm{s}$, which correspond to a Reynolds number, Re, in the channel of respectively 46,000 and 87,000.

\section{Results}

A typical result for the response of the bubble nucleation frequency, $f_{n u c}$, for an inter-site distance, $S$, of $2 \mathrm{~mm}$ is shown in

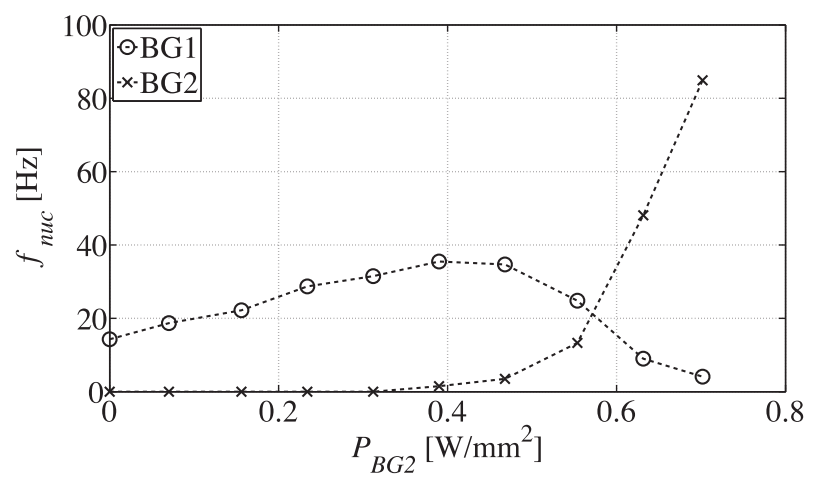

Fig. 7. Evolution of bubble frequency at BG1 with increasing power to BG2 for an inter-site distance $S=2 \mathrm{~mm}$. 
Fig. 7. The horizontal axes shows the power on the upstream bubble generator, BG2. As mentioned in the previous paragraph, the power on the downstream bubble generator, BG1, is kept constant during the experiments, as well as the bulk liquid temperature and pressure. The mean wall temperature, $T_{\text {wall }}$, of BG1 before activation of BG2 was $112 \pm 1{ }^{\circ} \mathrm{C}$. The Jakob number is defined as

$\mathrm{Ja}=\frac{c_{p, l} \rho_{l}\left(T_{\text {wall }}-T_{\text {sat }}\right)}{h_{f g} \rho_{v}}$,

in which $c_{p, l}$ is the specific heat capacity of the liquid, $\rho_{l}$ the liquid density, $\rho_{v}$ the vapor density, $T_{\text {sat }}$ the liquid saturation temperature and $h_{f g}$ the latent heat of evaporation. A wall temperature of $112 \pm 1{ }^{\circ} \mathrm{C}$ then gives a Jakob number of $34.6 \pm 2.9$.

As the power to BG2 increases, so does the bubble nucleation frequency at BG1. When the power to BG2 is large enough to initiate bubble nucleation at BG2 itself, $f_{n u c}$ at BG1 starts decreasing as the frequency of BG2 increases.

\subsection{Influence of inter-site distance}

The same experiments have been performed for increasing inter-site distance, the result of which can be seen in Fig. 8. The starting frequency for each distance was $12-14 \mathrm{~Hz}$ for these experiments. The error bars in the figure represent the standard error of the mean, see Eq. (5). For comprehensibility, the error bars are only shown for an inter-site distance of $6 \mathrm{~mm}$. The value of the standard error of the mean is approximately $0.5 \mathrm{~Hz}$ for all experiments. One important thing to stress here, is that BG1 in this analysis is always the same bubble generator, but BG2 is chosen further away with each step in $S$, i.e. physically different according to Fig. 2. Every bubble generator initiates bubble nucleation at a different power and also the bubble diameter at detachment varies from 1.2 to $2.0 \mathrm{~mm}$ for various bubble generators. The moment bubble nucleation initiation from BG2, $f_{B G 2}>1$, is shown by a filled marker.

The starting frequency at $P_{B G 2}=0 \mathrm{~W}$ is seen to vary between the different inter-site distance measurements. The total set of measurements in Fig. 8 took 3-4 h to complete. During this time, the system parameters (flow velocity, bulk pressure, and bulk temperature) are constant over time. The highest starting frequency is at an inter-site distance of $2 \mathrm{~mm}$ (with which the measurements started) and the lowest starting frequency is found at $S=10 \mathrm{~mm}$ (with which the measurements ended). In other words, these experiments have been performed in order, from 2 to $10 \mathrm{~mm}$ distance. The resulting spread in bubble release frequency can be caused by two mechanisms. First, the active nucleation site on the bubble generator surface can be gradually depleted over time. Second, the bubble generator surface topology is changing over

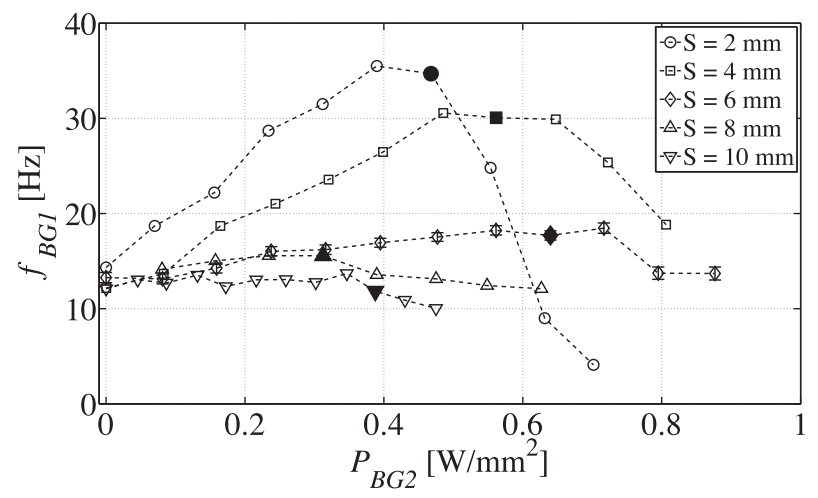

Fig. 8. Evolution of bubble frequency at BG1 with increasing power to BG2 for different inter-site distances $S$ for a starting frequency near $15 \mathrm{~Hz}$, filled markers indicate the onset of bubble nucleation on BG2. time. Small changes in the activation conditions of a natural site suffice to explain this spread in starting frequency.

For an inter-site distance of up to $8 \mathrm{~mm}$, the bubble frequency of BG1 significantly increases while BG2 is not creating its own bubbles. The largest effect is seen for distances of 2 and $4 \mathrm{~mm}$. A decrease in bubble frequency at BG1 can be seen for all inter-site distances after BG2 starts its own nucleation (filled marker).

A second observed effect is an increase in bubble detachment diameter, $D_{b}$, at downstream bubble generator BG1 with increasing power to BG2. Fig. 9 depicts a typical increase in $D_{b}$ as seen from a side-view recording during the experiments. Fig. 10 shows an increase in bubble detachment diameter for each inter-site distance, note that the line for $S=2 \mathrm{~mm}$ has been raised by $0.1 \mathrm{~mm}$ for clarity. The error bars again represent the standard error of the mean. The relative increase of the bubble diameter, $\left(D_{b, \max }-D_{b, 0}\right) / D_{b, 0}$ is shown in Table 1 for all inter-site distances. Diameter $D_{b, \max }$ is defined as the maximum bubble diameter at a certain $P_{B G 2, n u c}$ around which BG2 starts creating its own bubbles and $D_{b, 0}$ is the bubble diameter as observed without influence of BG2. The bubble diameter for $S=2 \mathrm{~mm}$ increases by around $19 \%$, until BG2 initiates nucleation. The detachment diameter was not quantified for vapor bubbles that are hydrodynamically and obviously affected in their growth, size and detachment by the proximity of bubbles originating from BG2. Because of this, $D_{b}$ is not shown for higher values of $P_{B G 2}$. The increase in bubble detachment size shows similarities to the increase in bubble frequency; compare Figs. 8 and 10. The most significant influence is seen in short inter-site distances of 2, 4 and $6 \mathrm{~mm}$. For the larger distances of 8 and $10 \mathrm{~mm}$, the bubble detachment diameter increase is relatively small.

\subsection{Influence of initial nucleation frequency}

Additional experiments were performed at a higher initial nucleation frequency at BG1, shown in Fig. 11. Before activation of BG2, the wall temperature of BG1 was $113 \pm 1{ }^{\circ} \mathrm{C}$. The Jakob number in this experiment is $37.5 \pm 2.9$, which is $8 \%$ higher than for the experiments at lower initial bubble nucleation frequency. An $8 \%$ increase in Ja leads to a doubling of the bubble frequency in the reported experiments. The trends are similar to the results for a lower starting frequency, see Fig. 8. However, the relative increase and decrease of the bubble nucleation frequency is smaller. A special note has to be made for $S=2 \mathrm{~mm}$, where BG2 initiated bubble nucleation from two separate nucleation sites, each of which is indicated by a filled marker.

Table 2 shows the relative increase in the bubble detachment diameter, $D_{b}$. Note that the increase is smaller compared to the lower initial nucleation frequency reported in Table 1 . It should also be noted that the increase for $S=2 \mathrm{~mm}$ is quite low, but this is caused by an early nucleation initiation at BG2 (i.e. a low $P_{B G 2, n u c}$ ).

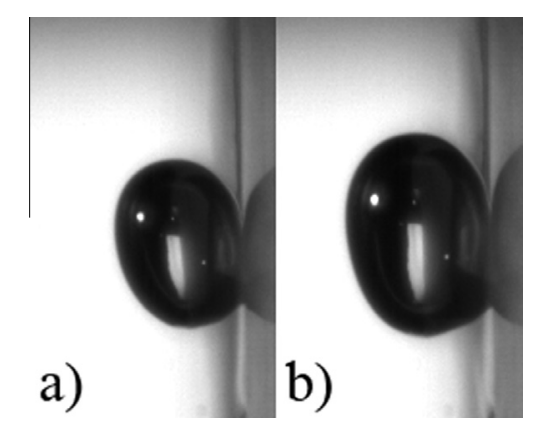

Fig. 9. Example of bubble diameter increase for an inter-site distance of $S=2 \mathrm{~mm}$. (Left) $P_{B G 2}=0 \mathrm{~W}, D_{b}=1.34 \mathrm{~mm}$; (Right) $P_{B G 2}=0.61 \mathrm{~W}, D_{b}=1.6 \mathrm{~mm}$ 


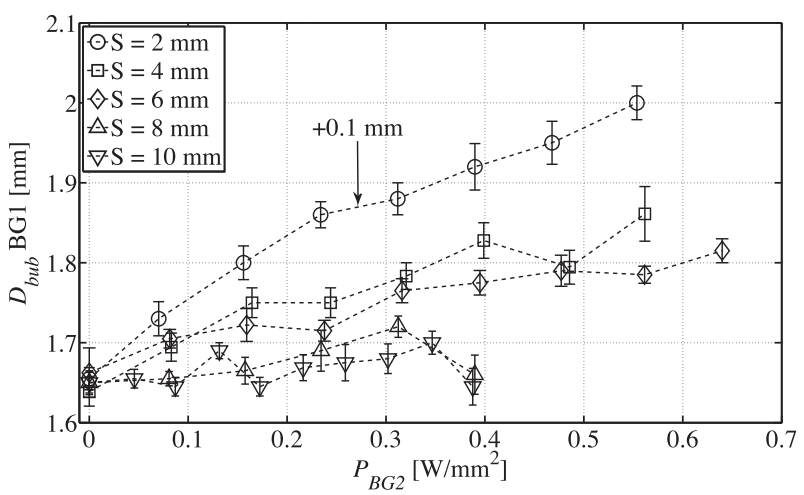

Fig. 10. Evolution of bubble diameter from BG1 with increasing power to BG2, corresponding to the measurements in Fig. 8, the line for $S=2 \mathrm{~mm}$ has been raised by $0.1 \mathrm{~mm}$ for clarity.

Table 1

Relative increase in $D_{b}$, the standard error of the mean is $\pm 2 \%$ at most (95\% confidence bounds), $v_{\text {bulk }}=0.45 \mathrm{~m} / \mathrm{s}$.

\begin{tabular}{clc}
\hline $\mathrm{S}[\mathrm{mm}]$ & $\mathrm{P}_{\mathrm{BG} 2 \text {,nuc }}[\mathrm{W}]$ & $\left(\mathrm{D}_{\mathrm{b}, \max }-\mathrm{D}_{\mathrm{b}, 0}\right) / \mathrm{D}_{\mathrm{b}, 0}[\%]$ \\
\hline 2 & 0.43 & 18.5 \\
4 & 0.56 & 13.4 \\
6 & 0.65 & 9.6 \\
8 & 0.32 & 3.6 \\
10 & 0.31 & 2.4 \\
\hline
\end{tabular}

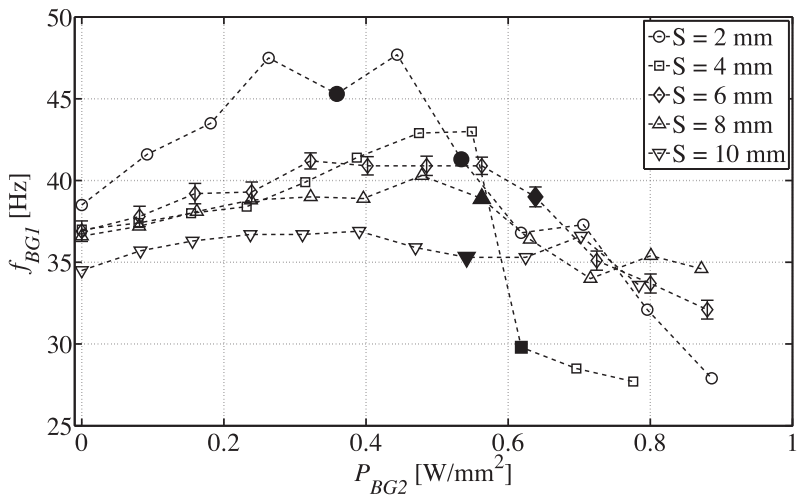

Fig. 11. Evolution of bubble frequency at BG1 with increasing power to BG2 for different inter-site distances $S$ for a starting frequency near $40 \mathrm{~Hz}$, filled markers indicate the onset of bubble nucleation on BG2.

Table 2

Relative increase in $D_{b}$ as observed during experiments at a higher initial nucleation frequency at BG1, the standard error of the mean is $\pm 2 \%$ at most (95\% confidence bounds), $v_{\text {bulk }}=0.45 \mathrm{~m} / \mathrm{s}$.

\begin{tabular}{cll}
\hline $\mathrm{S}[\mathrm{mm}]$ & $\mathrm{P}_{\mathrm{BG} 2, \text { nuc }}[\mathrm{W}]$ & $\left(\mathrm{D}_{\mathrm{b}, \max }-\mathrm{D}_{\mathrm{b}, 0}\right) / \mathrm{D}_{\mathrm{b}, 0}[\%]$ \\
\hline 2 & 0.26 & 7.1 \\
4 & 0.55 & 8.2 \\
6 & 0.56 & 3.7 \\
8 & 0.48 & 3.7 \\
10 & 0.47 & 2.3 \\
\hline
\end{tabular}

\subsection{Influence of flow rate}

As mentioned in the measurement strategy Section 2.4, the location of the active nucleation site on BG1 was different in the experiments performed at the higher flow rate $(0.85 \mathrm{~m} / \mathrm{s})$, as can be seen in Fig. 12.

The location is near the left edge of the heater area and bubbles originating from this location will, for almost half the bubble
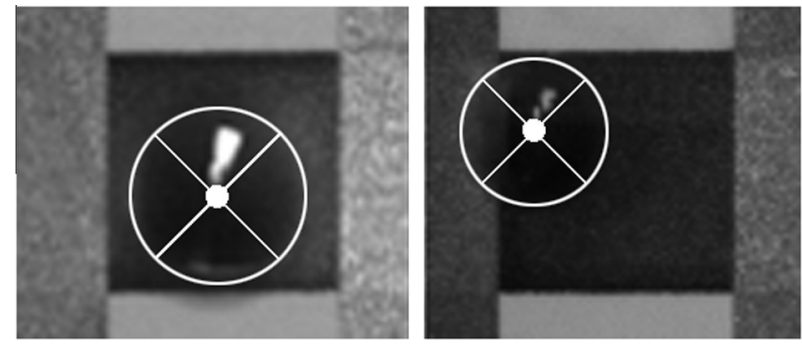

Fig. 12. Natural nucleation site locations on $B G 1$ observed during the experiments; (Left) $v_{\text {bulk }}=0.45 \mathrm{~m} / \mathrm{s}$; (Right) $v_{\text {bulk }}=0.85 \mathrm{~m} / \mathrm{s}$.

width, grow over the left edge of the heater. This means that the bubble will partially grow into a colder region of liquid. The difference in nucleation site is therefore part of the reason why bubbles originating from this location are smaller at detachment compared to bubbles formed at $v_{\text {bulk }}=0.45 \mathrm{~m} / \mathrm{s}$. For this reason, it is not unreasonable to think that, relatively, the trends in bubble frequency and bubble diameter would have been even more pronounced when the bubble nucleation location would still have been in the center of the bubble generator. Additionally, because the bulk flow velocity is higher, the bubble leaves the heater area faster (see [21]), and with a smaller bubble detachment size. The effect of nucleation site location would therefore be enhanced at lower bulk flow velocities, since bubbles grow larger and lean over the edge more.

The experiments for $v_{\text {bulk }}=0.85 \mathrm{~m} / \mathrm{s}$ have been performed at inter-site distances of 2, 6 and $10 \mathrm{~mm}$. The resulting frequency histories can be seen in Fig. 13. The observed trends are similar to the ones reported for lower flow rates (Fig. 8). Contrary to the lower flow rate is that even at a distance of $10 \mathrm{~mm}$ a significant increase in bubble frequency can be observed. Furthermore, the relative increase and decrease in bubble frequency at a distance of $2 \mathrm{~mm}$ is more severe, even leading to near complete deactivation of the nucleation site at BG1.

The relative mean bubble departure diameter for each inter-site distance at $v_{\text {bulk }}=0.85 \mathrm{~m} / \mathrm{s}$ are denoted in Table 3 . The increase is comparable to but slightly lower than the ones reported for $v_{\text {bulk }}=0.45 \mathrm{~m} / \mathrm{s}$ in Table 1 .

\section{Analysis}

All reported experiments in the results Section 3 show the same two trends with increasing $P_{B G 2}$ : (1) An increase in nucleation frequency and detachment diameter at BG1 before upstream bubble

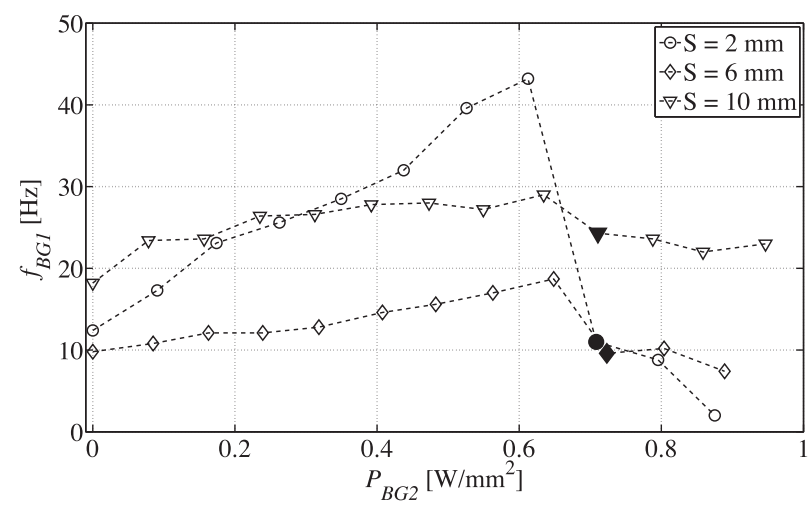

Fig. 13. Evolution of bubble frequency at BG1 with increasing power to BG2 for varying inter-site distance $S$ at $v_{\text {bulk }}=0.85 \mathrm{~m} / \mathrm{s}$, filled markers indicate the onset of bubble nucleation on BG2. 
Table 3

Relative increase in $D_{b}$ as observed during experiments at $v_{\text {bulk }}=0.85 \mathrm{~m} / \mathrm{s}$, the standard error of the mean is $\pm 2 \%$ at most ( $95 \%$ confidence bounds).

\begin{tabular}{clc}
\hline $\mathrm{S}[\mathrm{mm}]$ & $\mathrm{P}_{\mathrm{BG} 2, \text { nuc }}[\mathrm{W}]$ & $\left(\mathrm{D}_{\mathrm{b}, \max }-\mathrm{D}_{\mathrm{b}, 0}\right) / \mathrm{D}_{\mathrm{b}, 0}[\%]$ \\
\hline 2 & 0.62 & 17.9 \\
6 & 0.64 & 7.6 \\
10 & 0.66 & 4.7 \\
\hline
\end{tabular}

generator BG2 starts creating its own bubbles; (2) A decrease in nucleation frequency after BG2 initiates significant nucleation. First, these two general trends are discussed, after which the influence of inter-site distance, $S$, initial nucleation frequency at BG1, $f_{B G 1}$ and liquid bulk flow rate, $v_{\text {bulk }}$, are analyzed.

\subsection{Trend 1: increase in $f_{B G 1}$ and $D_{b}$}

The increase in bubble frequency at the downstream bubble generator, BG1, with increasing $P_{B G 2}$ until bubble nucleation commences at BG2 (Fig. 7) is explained by the increasing convective heat added to the liquid flow by BG2. Visualization of the heat originating from the bubble generators by a side-view camera is possible due to temperature gradients near the bubble generator surface, causing changes in refractive index. Based on these recordings, a schematic representation of this situation is drawn in Fig. 14.

The differences between the unheated and heated side views on the RHS of Fig. 14 give a demarcation line which borders the volume in which refractive indices have changed. This demarcation line is considered to be the edge of the experimental boundary layer. It will now be attempted to interpret the experimental boundary layer as a thermal boundary layer in two independent ways. First, the spatial development of the boundary layer thickness will be compared with those of theoretically predicted boundary layers. Next, the convective heat transfer coefficient will be determined, from the imposed heat flux to the bubble generator and from measured wall and bulk temperatures, and compared with the theoretical mean heat transfer coefficient. To start with, theoretical boundary layer development is computed as if the axial pressure gradient in the bulk is negligible. This assumption is fair since the ratio of boundary layer thickness to channel width does not exceed 0.003 and since the axial width of the boundary layer is $1 \mathrm{~mm}$, pressure varies by $0.1 \%$ only. Furthermore, the thermal
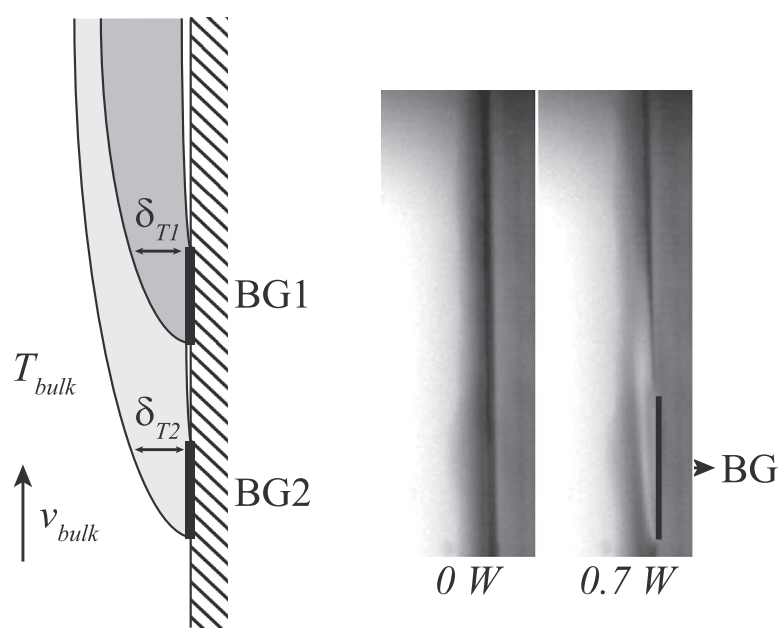

Fig. 14. (Left) Schematic of convective heat originating from BG1 and BG2; (Right) Two camera images of a bubble generator at respectively 0 and $0.7 \mathrm{~W}$. The heat originating from the bubble generator causes changes in the refractive index of the liquid. boundary layer is observed to become turbulent slightly downstream of the bubble generator. Boundary layer development at the bubble generator is therefore considered to be laminar. The well-known Blasius solution, see for example [22, Chap.7, p. 140], for the development of a hydrodynamic boundary layer $\left(\delta_{H}\right)$ for parallel flow past a flat plate at zero incidence, given by

$\delta_{H}(x)=5 \sqrt{\frac{\mu_{l} x}{\rho_{l} v_{\text {bulk }}}}$,

in which $\mu_{l}$ is the dynamic viscosity of the fluid and $x$ the distance from the start of the plate. For the current experiments, with water at $100^{\circ} \mathrm{C}$ flowing at $v_{\text {bulk }}=0.45 \mathrm{~m} / \mathrm{s}$, this equation becomes $\delta_{H}(x)=0.004 \sqrt{x}$ when taking $x$ as the distance from the start of the heated part. The relationship between $\delta_{H}$ and $\delta_{T}$ follows from the Pohlhausen solution as

$\delta_{T}(x)=\frac{\delta_{H}(x)}{\operatorname{Pr}^{1 / 3}}$,

Fig. 15 compares the measured boundary layer thickness, $\delta_{T}$, development with the free boundary layers of momentum (Blasius) and temperature (Pohlhausen). The measurement points in Fig. 15 are obtained by subtracting the images on the RHS of Fig. 14 and detecting the border of the volume in which the refractive index has changed as a result of temperature differences. The inaccuracy of the measurement is estimated as about one pixel or $15 \mu \mathrm{m}$. The measurement points are remarkably close to the $\delta_{H}$ predicted by the Blasius solution for a hydrodynamically developing flow past a flat plate. Although a striking similarity exists, the Pohlhausen solution for $\delta_{T}$ may be expected to be an underestimation, because the velocity profile in the experiments is already developed and heat originating from the wall penetrates more readily into the actual fluid flow in the direction perpendicular to the wall. A further confirmation of the boundary layer development is obtained from the measured heat flux from the bubble generator to the bulk, typically $0.5 \mathrm{MW} / \mathrm{m}^{2}$, and the measured temperature difference between the wall of the bubble generator and the bulk liquid, typically $15 \mathrm{~K}$. The resulting convective heat transfer coefficient, about 33,000 W/( $\left.\mathrm{m}^{2} \mathrm{~K}\right)$, can be compared with the mean heat transfer coefficient over the axial width of the bubble generator, $L$. According to the Pohlhausen solution the heat transfer coefficient is given by the Nusselt number, $\mathrm{Nu}$, relationship

$N u_{L}=\frac{\overline{h_{c}} L}{k_{l}}=0.664 \operatorname{Re}_{L}^{1 / 2} \operatorname{Pr}^{1 / 3}$,

in which $k_{l}$ is the thermal conductivity of the liquid, Re is the local Reynolds number along the length of the bubble generator and $\mathrm{Pr}$ is the Prandtl number for the bulk liquid ( 1.75 for water at $100{ }^{\circ} \mathrm{C}$ ). This yields a convective heat transfer coefficient of about $19200 \mathrm{~W} /\left(\mathrm{m}^{2} \mathrm{~K}\right)$. Apparently, the finite size of the 1 by $1 \mathrm{~mm}^{2}$ bubble generator allows for refreshing of fluid from the sides of the bubble generator. Boundary layer development in the direction of the flow varies in depth, i.e. into Fig. 15. However, the above analysis makes clear that actual thermal boundary layer development

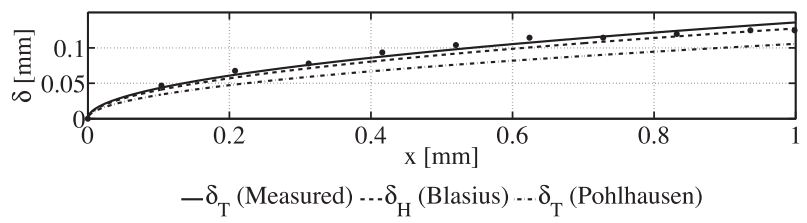

Fig. 15. Comparison of the measured demarcation line (dots fitted by solid line) to the hydrodynamic (dashed line) and thermal (dash-dot line) boundary layer development on a flat plate approached by a constant velocity profile. 
can well be predicted by Blasius type of equations, which will facilitate generalization of the findings to other flow conditions.

As a consequence of the increased convective heat, the thickness of the thermal boundary layer at BG1, $\delta_{T 1}$, and the average temperature in the volume adjacent to BG1 in the boundary layer, $\overline{\Delta T}$, increase with increasing $P_{B G 2}$. The heat convection from the upstream bubble generator promotes nucleation at the downstream site, BG1.

When increasing the inter-site distance the added convection keeps showing a significant contribution to the promotion of bubble nucleation, but the largest effect can be seen for distances of 2 and $4 \mathrm{~mm}$, see Fig. 8. At larger distances, the added heat is partially mixed into the bulk liquid flow and its contribution rapidly decreases.

The increase in bubble frequency at BG1 relatively diminishes when the initial bubble nucleation frequency at BG1 increases, as can be concluded when comparing Figs. 8 and 11. The added convective heat from BG2 is partly consumed and diverted away by nucleating bubbles from BG1, which consequently decreases the extra energy available in the boundary layer connected to $\overline{\Delta T}$. Obviously, this effect is more pronounced at higher bubble frequencies at BG1.

For the higher flow rate, the relative increase in bubble nucleation frequency is higher for all reported inter-site distances, as can be seen from Figs. 8 and 13. This is as expected, since heat generated at BG2 reaches BG1 faster and has less time to diffuse into the bulk liquid. It can also be concluded that the second trend, which inhibits bubble nucleation at BG1, is so strong that for the smallest inter-site distance, $S=2 \mathrm{~mm}$, that it nearly deactivates bubble generation at BG1. Even for larger inter-site distances, a significant decrease in bubble frequency is still observed, but bubbles from BG2 passed by BG1 at a too large distance to make a difference as compared to $v_{\text {bulk }}=0.45 \mathrm{~m} / \mathrm{s}$.

The relative increase in bubble frequency is summarized in Table 4 for each observed case described in the results Section 3. Only values for inter-site distances $S=2,4$ and $6 \mathrm{~mm}$ are compared, since the measurement at the higher flow rate was only done for these inter-site distances. From these figures, it is clear that the largest increase can be expected for high flow rates and low starting bubble frequencies (i.e. at the onset of nucleate boiling (ONB)).

The increase in $D_{b}$, as shown in Figs. 9 and 10, is also explained by added convective heat. The thickness and mean temperature of the thermal boundary layer at BG1 increase, which allows the bubbles nucleating at BG1 to grow larger before detachment. The bubble detachment diameter seems to decrease after onset of significant nucleation from BG2, but since the bubble shapes at BG1 are hydrodynamically affected by bubbles from BG2, no conclusions can be drawn in this regard.

With increasing inter-site distance, the same trend is observed in $D_{b}$ as for $f_{B G 1}$, see Fig. 10 and Table 1, i.e. the relative increase in bubble diameter decreases. The influence of added convection originating from BG2 diminishes with increasing $S$. For $v_{\text {bulk }}=0.45 \mathrm{~m} / \mathrm{s}$, the added convection has almost no influence

Table 4

Relative increase of $f_{B G 1}$ as observed during the experiments for the following cases: (1) Initial $f_{B G 1}=13 \mathrm{~Hz}, v_{\text {bulk }}=0.45 \mathrm{~m} / \mathrm{s}$; (2) Initial $f_{B G 1}=37 \mathrm{~Hz}, v_{\text {bulk }}=0.45 \mathrm{~m} / \mathrm{s}$; (3) Initial $f_{B G 1}=14 \mathrm{~Hz}, v_{\text {bulk }}=0.85 \mathrm{~m} / \mathrm{s}$.

\begin{tabular}{cccc}
\hline $\mathrm{S}[\mathrm{mm}]$ & $\begin{array}{l}f_{B G 1} \text { increase(Case 1) } \\
{[\%]}\end{array}$ & $\begin{array}{l}f_{B G 1} \text { increase(Case 2) } \\
{[\%]}\end{array}$ & $\begin{array}{l}f_{B G 1} \text { increase(Case 3) } \\
{[\%]}\end{array}$ \\
\hline 2 & 157 & 23 & 258 \\
6 & 38 & 12 & 90 \\
10 & 8 & 7 & 61 \\
\hline
\end{tabular}

on the larger distances of 8 and $10 \mathrm{~mm}$ anymore, since most of the heat is diffused away into the bulk flow.

The relative increase in detachment diameter for the higher initial nucleation frequency measurement (see Fig. 11 and Table 2) and the higher velocity measurement (see Fig. 13 and Table 3 ) have the same trend with a similar relative increase as the measurement at lower initial nucleation frequency and bulk liquid velocity. Bubbles at the higher flow rate did not receive the full added convective heat since they partially grew over the heater edge, see the results Section 3. No quantitative conclusions can therefore be drawn when comparing bubble diameters at different flow rates.

\subsection{Trend 2: decrease in $f_{B G 1}$}

When BG2 starts creating vapor bubbles of its own, the bubble frequency of BG1 starts decreasing. The explanation for this is has three combined reasons:

- The added convective heat that BG1 was receiving from BG2 is suddenly lower because the vapor bubbles in BG2 are consuming this heat for their own growth.

- When a vapor bubble originating from the upstream bubble generator moves towards and passes by BG1, it scavenges away the heat in the thermal boundary layer of BG1 for additional evaporation which leads to an increase in size of this bubble. As a result, the mean temperature of the boundary layer at BG1 is lowered. For this effect to be significant, the bubble must travel close to the thermal boundary layer $\left(\delta_{T}\right.$ is roughly $0.1 \mathrm{~mm}$ in the reported experiments, see Fig. 15). An example is shown in Fig. 16. This effect inhibits the nucleation of new bubbles at BG1.

- When a bubble passes by BG1, its low pressure wake will enhance mixing and will direct hot liquid away from the surface. Convective heat transfer from BG1 is enhanced. This effect has been shown to be significant by Kenning and Kao [23], who injected nitrogen bubbles into a single phase upward flow past a heated wall and found that the heat transfer coefficient from the wall to the liquid was enhanced by up to $50 \%$.

The inhibitive effect of bubbles passing by BG1 is observed for every inter-site distance. Unlike the convective promotion, the inhibitive effect is present even for $S=10 \mathrm{~mm}$. This effect is expected to play a role at even larger distances than reported here, although it depends on the flow direction. In the reported experiments, the flow is vertically upward with respect to gravity. The lift force on isolated bubbles originating from upstream generator BG2 acts in the direction of the wall, as shown by Tomiyama et al. [24] to be valid for Eötvös number, Eo, $<4$, corresponding to $D_{\text {bub }}<5 \mathrm{~mm}$. Therefore, the lift force is the driving action that explains why bubbles are observed to move towards the wall as they flow upward. This, in turn, means that the vapor bubbles travel at close proximity past other nucleation sites downstream, inhibiting bubble nucleation there.

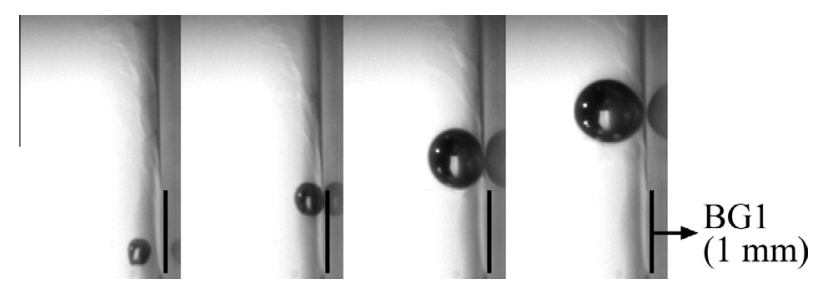

Fig. 16. A bubble originating from BG2 traveling in close proximity to BG1 (indicated by a vertical black line) and scavenging away heat; the time between consecutive frames is $1 \mathrm{~ms}$. 
In a downward flow configuration, this inhibitive effect is expected to play a smaller role, since bubbles will be forced toward the center of the bulk flow. However, even though an upward flow configuration may lead to less active nucleation sites, the bubbles become larger in upflow than in downflow as they travel more closely to the heated wall. This effect was also observed by Thorncroft \& Klausner [25], who concluded that vapor bubbles in upflow boiling grow larger as compared to downflow boiling because bubbles travel close to the heated wall. They also observed a lower number of active nucleation sites in upflow boiling, which suggests that inhibition of nucleation sites was more prominent in upflow. At the same time they concluded that the heat transfer per active site was significantly larger in upflow, because bubbles would grow larger while traveling close to the heated wall. Therefore, it should not be concluded that downflow boiling leads to enhancement of heat transfer in comparison to upflow boiling, even though downflow boiling is expected to have more nucleation sites when applying the same fluid flow rate and heat flux.

When the initial bubble nucleation frequency of BG1 is higher, the relative decrease in bubble frequency under influence of bubbles originating from BG2 is lower. Bubbles and convective heat originating from $\mathrm{BG} 2$ are diverted away from the surface of BG1 and do not have the opportunity to remove heat by the mechanisms mentioned in the above list. Obviously, this effect will be larger for even higher bubble frequencies at BG1, which consequently causes both the promotive and inhibitive trends to be less prominent.

At the higher flow rate for an inter-site distance of $S=2 \mathrm{~mm}$, the nucleation site on BG1 was almost completely deactivated by bubbles originating from the upstream generator. The extend of inhibition of nucleation is dependent on the distance at which bubbles from BG2 travel past BG1. For this reason, the inhibition was much less significant at larger inter-site distances, but is still expected to play a role at virtually any inter-site distance, as long as the bubbles travel in close proximity to the downstream nucleation site.

From pool boiling experiments, short distance nucleation site interactions were already known to be the consequence of hydrodynamic interactions of neighboring bubbles and conduction in the substrate. This obviously affects the number of active nucleation sites. Short-distance interaction of this kind is expected to play a similar role in forced convective boiling. However, the present study has shown that hydrodynamic nucleation site interactions play a significant role at even larger distances in flow boiling. Hydrodynamic interaction is prolonged by the advection of bubbles to other nucleation sites.

In order to predict the site-to-site interaction at other site distances and for other liquid mass flow rates than examined in the above, the boundary layer development from the upstream site must be predicted, as well as trajectories of bubbles originating from this and other upstream sites. When entering the thermal boundary layer next to another nucleation site, bubbles will extract heat from this layer and site-to-site interaction occurs. The boundary layer development close to the upstream bubble generator has been found to be well predictable by Blasius type of equations, but more downstream and in other flow configurations other boundary layer development must be anticipated.

\section{Conclusions}

Depending on mass flow rate, flow direction and heat fluxes to both bubble generators, two nucleation sites have been shown to interact even at the largest observed distance of $10 \mathrm{~mm}$. However, interactions are believed to play a role at any distance, as long as already produced vapor bubbles travel in close proximity to other nucleation sites. The results have shown the following two major trends.

The first trend is an increase in bubble nucleation frequency, $f_{B G 1}$, and bubble detachment diameter, $D_{b}$, at a downstream bubble generator (BG1) caused by additional convection (not caused by bubbles) from an upstream bubble generator, BG2, as schematized in Fig. 14. The influence of additional convection on bubble frequency and diameter diminishes with increasing inter-site distance, $S$, and initial bubble nucleation frequency at BG1. The influence of added convective heat is shown to be enhanced by increasing the liquid bulk flow rate.

The second trend is seen when upstream bubble generator, BG2, initiates its own bubble nucleation. Vapor bubbles that nucleate at BG2 and pass by BG1 in close proximity have an inhibitive effect on bubble nucleation at BG1, because they remove part of the heat in the thermal boundary layer at BG1. It is concluded that inhibition of bubble nucleation should occur at any nucleation site which is approximated by vapor bubbles originating from upstream sites and is therefore not particularly dependent of inter-site distance $S$. Additionally, the effect of this inhibitive trend diminishes with increasing $f_{\text {bub }}$ at the downstream nucleation site BG1.

With respect to horizontal nucleation site interactions in upward flow boiling, as briefly discussed in Section 2.2, the only conclusion that can be drawn is that there are no horizontal nucleation site interactions for $S / D_{b} \geqslant 1.33$. No smaller $S / D_{b}$ in horizontal nucleation site distances have been studied. However, it is to be expected that when $S / D_{b}<1$ bubbles will influence each other hydrodynamically and may coalesce.

Because of the significance of the effect of hydrodynamic interaction on the number of active nucleation sites and bubble size at detachment, mechanistic modeling of nucleate flow boiling is expected to benefit from the above findings.

\section{Conflict of interest}

None declared.

\section{Acknowledgments}

This research is supported by the Dutch Technology Foundation STW, which is part of the Netherlands Organisation for Scientific Research (NWO), and which is partly funded by the Ministry of Economic Affairs. Furthermore, this work is conducted under the umbrella of the COST MP1106 Action: Smart and Green Interfaces - from single bubbles and drops to industrial, environmental, and biomedical applications.

\section{References}

[1] J.C. Chen, Correlation for boiling heat transfer to saturated fluids in convective flow, Ind. Eng. Chem. 5 (3) (1966) 322-329.

[2] P. Stephan, J. Hammer, A new model for nucleate boiling heat transfer, Wärmeund Stoffübertragung 30 (1994) 119-125.

[3] H. Steiner, A. Kobor, L. Gebhard, A wall heat transfer model for subcooled flow boiling, Int. J. Heat Mass Transfer 48 (2004) 4161-4173.

[4] N. Basu, G.R. Warrier, V.K. Dhir, Wall heat flux partitioning during subcooled flow boiling: part 1 - model development, J. Heat Transfer 127 (2005) 131140.

[5] J.P. Kroes, C.W.M. Van der Geld, E. Van Velthooven, Evaluation of four nucleate flow boiling models, Adv. Multiphase Flow Heat Transfer 1 (2009) 267-283.

[6] S. Moghaddam, K. Kiger, Physical mechanisms of heat transfer during single bubble nucleate boiling of fc-72 under saturation conditions-ii. theoretical analysis, Int. J. Heat Mass Transfer 52 (2009) 1295-1303.

[7] N. Zuber, Nucleate boiling, the region of isolated bubbles and the similarity with natural convection, Int. J. Heat Mass Transfer 6 (1963) 53-78.

[8] V.V. Chekanov, Interaction of centers in nucleate boiling, Teplofizika Vysokikh Temperatur 15 (1) (1977) 121-128.

[9] A. Calka, R.L. Judd, Some aspects of the interaction among nucleation sites during saturated nucleate boiling, Int. J. Heat Mass Transfer 28 (12) (1985) 2331-2342. 
[10] D.B.R. Kenning, V.H. Del Valle M, Fully-developed nucleate boiling: overlap of areas of influence and interference between bubble sites, Int. J. Heat Mass Transfer 24 (6) (1981) 1025-1032.

[11] J. Bonjour, M. Clausse, M. Lallemand, Experimental study of the coalescence phenomenon during nucleate pool boiling, Exp. Thermal Fluid Sci. 20 (2000) 180-187.

[12] L. Zhang, M. Shoji, Nucleation site interaction in pool boiling on the artificial surface, Int. J. Heat Mass Transfer 46 (2003) 513-522.

[13] A. Mukherjee, V.K. Dhir, Study of lateral merger of vapor bubbles during nucleate pool boiling, J. Heat Transfer 126 (2004) 1023-1039.

[14] S. Siedel, S. Cioulachtjian, J. Bonjour, Experimental analysis of bubble growth, departure and interactions during pool boiling on artificial nucleation sites, Exp. Thermal Fluid Sci. 32 (2008) 1504-1511.

[15] I. Golobič, J. Petkovsek, D.B.R. Kenning, Bubble growth and horizontal coalescence in saturated pool boiling on a titanium foil, investigated by high-speed ir thermography, Int. J. Heat Mass Transfer 55 (2012) 1385-1402.

[16] A. Luke, Interactions between bubble formation and heating surface in nucleate boiling, Exp. Thermal Fluid Sci. 35 (2011) 753-761.
17] N.D. Nimkar, S.H. Bhavnani, R.C. Jaeger, Effect of nucleation site spacing on the pool boiling characteristics of a structured surface, Int. J. Heat Mass Transfer 49 (2006) 2829-2839.

[18] M.J. Donachie Jr., Titanium - A Technical Guide, second ed., ASM International, 2000.

[19] R.B. Belser, W.H. Hicklin, Temperature coefficients of resistance of metallic films in the temperature range of $20^{\circ}-600{ }^{\circ} \mathrm{C}$, J. Appl. Phys. 30 (1959) $313-322$

[20] A.V. Luikov, Analytical Heat Diffusion Theory, Academic Press, 1968.

[21] C.H.M. Baltis, C.W.M. Van der Geld, Heat transfer mechanisms of a vapor bubble growing at a wall in saturated upward flow, submitted, 2014.

[22] H. Schlichting, Boundary Layer Theory, McGraw-Hill Book Company, 1979.

23] D.B.R. Kenning, Y.S. Kao, Convective heat transfer to water containing bubbles: enhancement not dependent on thermocapillarity, Int. J. Heat Mass Transfer 15 (1972) 1709-1717.

[24] A. Tomiyama, H. Tamai, I. Zun, S. Hosokawa, Transverse migration of single bubbles in simple shear flows, Chem. Eng. Sci. 57 (2002) 1849-1858.

[25] G.E. Thorncroft, J.F. Klausner, The influence of vapor bubble sliding on forced convection boiling heat transfer, J. Heat Transfer 121 (1999) 73-79. 